\title{
BMJ Students' attitude and smoking OPen behaviour following the implementation of a university smoke-free policy: a cross-sectional study
}

\author{
Monique Chaaya, ${ }^{1}$ Maysam Alameddine, ${ }^{1}$ Rima Nakkash, ${ }^{2}$ Rima A Afifi, ${ }^{2}$ \\ Joanna Khalil, ${ }^{2}$ Georges Nahhas ${ }^{1}$
}

To cite: Chaaya $M$, Alameddine M, Nakkash R, et al. Students' attitude and smoking behaviour following the implementation of a university smoke-free policy: a cross-sectional study. BMJ Open 2013:3:e002100. doi:10.1136/bmjopen-2012002100

- Prepublication history for this paper are available online. To view these files please visit the journal online (http://dx.doi.org/10.1136/ bmjopen-2012-002100).

Received 4 October 2012 Revised 5 March 2013 Accepted 7 March 2013

This final article is available for use under the terms of the Creative Commons Attribution Non-Commercial 2.0 Licence; see http://bmjopen.bmj.com

${ }^{1}$ Department of Epidemiology and Population Health, Faculty of Health Sciences, American University of Beirut, Beirut, Lebanon

${ }^{2}$ Department of Health Promotion and Community Health, Faculty of Health Sciences, American University of Beirut, Beirut, Lebanon

\section{Correspondence to} Professor Monique Chaaya; mchaaya@aub.edu.lb

\section{ABSTRACT}

Objective: In view of the high-smoking rate among university students in Lebanon and the known adverse effects of second-hand smoking, the American University of Beirut (AUB) decided to implement a non-smoking policy on campus. This study sought to examine the students' compliance and attitudes following the ban.

Design: Cross-sectional study.

Setting: A private university in Lebanon.

Participants: 545 randomly selected students were approached. A stratified cluster sample of classes offered in the spring semester of the 2008/2009 academic year was selected. Students completed a self-administered paper and pencil survey during class time.

Primary and secondary outcome measures: The main outcomes were compliance with and attitudes towards the ban. Other secondary outcomes were the perception of barriers to implementation of the ban and attitudes towards tobacco control in general.

Results: 535 students participated in the study. Smokers were generally compliant with the ban $(72.7 \%)$ and for some $(20 \%)$ it led to a decrease in their smoking. Students' attitude towards the ban and the enforcement of a non-smoking policy in public places across Lebanon varied according to their smoking status whereby non-smokers possessed a more favourable attitude and strongly supported such policies compared with smokers; overall, the largest proportions of students were satisfied to a large extent with the ban and considered it justified $(58.6 \%$ and $57.2 \%$, respectively). While much smaller percentages reported that the ban would help in reducing smoking to a large extent $(16.7 \%)$ or it would help smokers quit $(7.4 \%)$. Perceived barriers to implementation of the non-smoking policy in AUB included the lack of compliance with and strict enforcement of the policy as well as the small number and crowdedness of the smoking areas.

Conclusions: An education campaign, smoking cessation services and strict enforcement of the policy might be necessary to boost its effect in further reducing students' cigarette use.

\section{ARTICLE SUMMARY}

Article focus

- To examine students' compliance and attitude following the smoking ban at the American University of Beirut campus.

Key messages

- Students are an important group to consider when discussing tobacco control and implementing a university wide smoking ban. They should be included as stakeholders in the analysis of the policy process.

- Implementing a tobacco-control policy in a university campus could be successful. Compliance and satisfaction were reasonably high, with some differentials according to smoking status.

- Challenges of the implementation of a tobaccocessation policy at a university could be overcome by having a comprehensive national tobacco-control policy.

Strengths and limitations of this study

- A representative large sample $(n=535)$ of students from all faculties.

- This study was the first to be conducted regionally.

- It is the first study to document student perceptions of barriers to smoke bans.

- This study could lay the ground for implementing smoking ban in other universities in Lebanon and globally.

- The cross-sectional nature of the study makes it difficult to ascertain the causal association between the smoking ban and smoking behaviour.

\section{INTRODUCTION}

The university years are an important life phase for every student during which they develop and engage in risky behaviours such as smoking. Smoking therefore is an important public-health problem among university students. An international study showed that 
overall $34 \%$ of male university students and $27 \%$ of female university students from 23 different countries were current smokers with large differences between countries and gender. ${ }^{1}$ Students from Southern European countries, for example, Portugal $(47 \%$ of males smoke) and Spain (46\% of females smoke), exhibited the highest rate of tobacco smoking compared with students from developing countries, for example, Thailand (men $14 \%$ and women $2 \%$ ), who displayed the lowest rates. ${ }^{1}$ Among US college students, the American College Health Association survey results ${ }^{2}$ revealed that $14.3 \%$ of students currently used tobacco, cigarettes being the most common form of tobacco use. ${ }^{1}$ In Lebanon, a study ${ }^{3}$ revealed that $28.3 \%$ of students in a private university currently smoked nargileh, of whom $38 \%$ were regular smokers, the proportion of lifetimenargileh smokers being $43 \% .^{3}$ Another study by Tamim et $a l^{4}$ showed that $40 \%$ of students in public and private universities in Lebanon currently smoked tobacco (21.1\% narghileh, $7.6 \%$ cigarettes and $11.3 \%$ smoked both cigarettes and narghileh). ${ }^{4}$ The aforementioned studies highlight the need for interventions that do not only target university students' smoking behaviour but also protect non-smokers from exposure to high levels of second-hand smoke and its associated health effects.

Evidence indicates that second hand smoking is associated with increased incidence of cardiovascular diseases, lung cancers and respiratory problems such as worsened asthma severity. ${ }^{5-8}$ To lessen these effects, nonsmoking policies in public places have been implemented and were shown to help reduce smoking among smokers ${ }^{9}{ }^{10}$ and second hand exposure to nonsmokers. ${ }^{11} 12$ A review of 26 studies on the effects of smoke-free workplaces in the USA, Australia, Canada and Germany showed that smoke-free workplaces are associated with decreased smoking prevalence and less cigarette consumption among smokers. ${ }^{9}$ Similarly, a nationally representative sample of college students in different US colleges showed that residents of smokefree housing had a significantly lower smoking prevalence than students living in residences which permit smoking. ${ }^{10}$ Not only do non-smoking policies encourage smokers to decrease or even quit smoking, but they also protect smokers and non-smokers from the effects of second-hand smoking. For example, a ban on smoking in workplaces and public places in Bowling Green, Ohio led to a significant reduction in hospital admission rates for coronary heart disease. ${ }^{11}$ Similarly, a smoke-free legislation in public places in Scotland was associated with a $17 \%$ decrease in admissions for acute coronary syndrome. ${ }^{12}$ This decrease was greatest among non-smokers whose exposure to second-hand smoke was dramatically reduced; a lower decline in acute coronary syndrome was observed for smokers. ${ }^{12}$

The purpose of this paper was to examine the implementation of a smoking ban on a private university in Lebanon. Although Lebanon ratified the WHO Framework Convention on Tobacco Control (FCTC) in
2005 which proposes a complete ban on indoor smoking, such a policy has only been implemented in 2012. In 2008, a few workplaces, hospitality venues, and educational institutions voluntarily introduced smoking bans. ${ }^{13}$ In May 2008, the American University of Beirut (AUB), a private university, decided to implement a non-smoking policy everywhere on campus encompassing student residence halls and all campus buildings except for private Faculty residences. Smoking became restricted to designated areas only. The specific objectives of the study were to: (1) assess the compliance with the ban; (2) assess the changes in smoking behaviour after the ban; (3) examine the student's attitude and opinion towards the campus-wide smoking ban and tobacco-control measures in general and (4) assess the perceptions of barriers to implementation of the ban.

\section{METHODS}

This study took place between October 2008 and June 2009. IRB approval was obtained from AUB for all research procedures.

\section{Participants}

A cross-sectional study was conducted at AUB, the largest private university in Lebanon and extending over 73 acres in the capital city. Founded in 1866 by American missionaries, AUB comprises six faculties, over 100 undergraduate/graduate programmes, and currently enrols around 7500 students from 69 countries. A random sample of classes being offered in the spring semester of academic year 2008/2009 was selected to recruit participants; a total of 545 students were registered in those classes. None of the instructors refused to allow recruitment in their classrooms. The selection of classes was based on a stratified cluster design whereby a proportionate sample of classes was chosen from all six faculties based on the size of each faculty. All students attending chosen classes were approached and asked to complete the survey.

\section{Survey and data collection}

Survey construction and data collection were done as part of the requirements for 'Survey Methods', a course offered at the Faculty of Health Sciences to undergraduate Environmental Health students. A self-administered paper and pencil survey in English was designed to collect data on demographic variables (age, gender, faculty, class, nationality and place of residence), personal smoking habits, compliance and attitude towards the smoking ban at AUB, in addition to students' attitude towards tobacco-control policies in Lebanon. Students were asked questions such as: to what extent were they satisfied with the smoking ban at AUB, whether they felt it was justified and whether the ban helped in creating a healthier environment. Survey questions related to their attitude towards some of the FCTC measures, specifically policies banning cigarette smoking in public places were 
included. Students expressed their support for or objection towards the enforcement of these policies using a Likert scale. The survey also included questions on lifetime and regular cigarette-smoking behaviour and perceived change in consumption following the ban, as well as their compliance with it (eg, whether they smoked in designated and non-designated areas). Moreover, students were asked about the barriers against the implementation of tobacco-control policies in AUB.

Instructors of the selected courses were contacted to ensure access to their class and set a time for data collection. Surveys were administered to students during class time.

\section{Data analysis}

Univariate analyses were performed to examine the distribution of main demographic and smoking variables. Bivariate analyses by gender and cigarette-smoking status were performed. $\chi^{2}$ tests and fisher's exact test were computed to check for significant differences in compliance and attitudes according to gender and smoking groups. $\mathrm{p}$ Values were reported as $<0.05,<0.01$ or $<0.001$. As occasional smokers and ex-smokers constituted only $6.4 \%$ and $4.7 \%$ of the sample, respectively, and their smoking exposure is different from regular smokers, smoking status was grouped into three categories: never smokers, occasional and ex-smokers and regular smokers. The response categories of the attitudes questions towards the ban were also classified into three groups: to a large extent, to some extent and not at all/ not sure. Oversampling from the Faculty of Health Sciences was adjusted for in the analyses by weighing all data according to the distribution of students in all six faculties. Weighted-absolute frequencies and percentages are presented in the tables.

\section{RESULTS}

Of the 545 students approached, fewer than $2 \%$ refused to participate. The final sample included 535 participants of which $25 \%$ were foreigners. The sample was representative of all undergraduate and graduate students from the six faculties at AUB, with an oversampling from the Faculty of Health Sciences.

Table 1 presents the basic characteristics of the total sample and according to smoking status. Participants tended to be between 19 and 24 years of age (80.8\%), Lebanese $(75 \%)$, women (59\%), from the Faculty of Arts and Sciences (41\%), and not living in dorms $(87 \%)$. Almost one-half of the surveyed students reported lifetime smoking cigarettes. Twenty per cent smoked in the past 30 days, $51 \%$ of whom were regular smokers ( $11 \%$ of the whole sample), $22 \%$ ex-smokers and 28\% occasional smokers. The largest proportion of students started smoking before joining the university $(75 \%)$, and another considerable percentage considered themselves addicted to smoking $(61 \%$ of regular

Table 1 Students' characteristics by smoking status

\begin{tabular}{|c|c|c|c|c|c|c|c|c|}
\hline \multirow[b]{2}{*}{ Variable } & \multicolumn{2}{|l|}{ Total } & \multicolumn{2}{|c|}{ Regular smokers } & \multicolumn{2}{|c|}{$\begin{array}{l}\text { Occasional and } \\
\text { ex-smokers }\end{array}$} & \multicolumn{2}{|c|}{ Non-smokers } \\
\hline & $\mathrm{n}=535$ & Per cent & $\mathrm{n}=60$ & Per cent & $\mathrm{n}=59$ & Per cent & $\mathrm{n}=416$ & Per cent \\
\hline$<18$ & 62 & 11.6 & 4 & 6.5 & 8 & 12.9 & 50 & 80.6 \\
\hline $19-24$ & 432 & 80.7 & 52 & 12.0 & 41 & 9.5 & 339 & 78.5 \\
\hline $25+$ & 41 & 7.7 & 4 & 9.8 & 10 & 24.4 & 27 & 65.9 \\
\hline Females & 318 & 59.6 & 21 & 6.6 & 30 & 9.4 & 267 & 84.0 \\
\hline \multicolumn{9}{|l|}{ Student's level } \\
\hline Freshman & 28 & 5.2 & 3 & 10.7 & 7 & 25.0 & 18 & 64.3 \\
\hline Sophomore & 83 & 15.5 & 13 & 15.7 & 5 & 6.0 & 65 & 78.3 \\
\hline Junior & 110 & 20.6 & 11 & 10.0 & 14 & 12.7 & 85 & 77.3 \\
\hline Agriculture and food sciences & 48 & 8.9 & 5 & 10.4 & 3 & 6.2 & 40 & 83.3 \\
\hline Engineering and architecture & 140 & 26.2 & 11 & 7.9 & 12 & 8.6 & 117 & 83.6 \\
\hline School of business & 91 & 17.0 & 13 & 14.3 & 11 & 12.1 & 67 & 73.6 \\
\hline Health sciences & 22 & 4.1 & 1 & 4.5 & 2 & 9.1 & 19 & 86.4 \\
\hline School of nursing & 11 & 2.0 & 1 & 9.1 & 2 & 18.2 & 8 & 72.7 \\
\hline \multicolumn{9}{|l|}{ Nationality } \\
\hline Lebanese & 397 & 74.5 & 42 & 10.6 & 41 & 10.3 & 314 & 79.1 \\
\hline Non-Lebanese & 72 & 13.5 & 10 & 13.9 & 8 & 11.1 & 54 & 75.0 \\
\hline Both Nationalities & 64 & 12.0 & 8 & 12.5 & 9 & 14.1 & 47 & 73.4 \\
\hline
\end{tabular}


smokers). One-third of regular smokers considered quitting in the next 6 months. Differences in smoking status were noted across faculties, year in university and gender. The highest prevalence of regular smoking was reported in the School of Business (14\%) followed by the Faculty of Arts and Sciences (13\%). The lowest prevalence was in the Faculty of Health Sciences (4.5\%). Sophomore and male students were more likely to be regular smokers than students from other levels and women, respectively.

\section{Compliance and students' smoking behaviour following implementation of the smoke-free policy}

Students' compliance with the ban was assessed among regular smokers. Almost three-quarters of the smokers abided by the policy and no significant difference was observed between men and women. In particular, $75 \%$ of male respondents reported only smoking in designated areas compared with $68.4 \%$ of female respondents. Further, 17\% of smokers reported receiving a warning ticket for smoking in a non-designated area (table 2).

As for students' smoking frequency following the ban, it did not significantly differ between genders. An equal proportion of male and female students (20\%) reported that their overall smoking decreased following the ban as compared with before its implementation. However, $31.4 \%$ and $5 \%$ of male and female respondents, respectively, indicated that their smoking increased, contrary to our expectations. On the other hand, the proportion of regular smokers reporting spending less time at AUB was significantly higher than that of non-smokers $(37.3 \%$ vs $2 \%)$ after the implementation of the smokefree policy.

\section{Students' attitude towards the smoke-free policy}

Table 3 reports the attitudes of students towards the smoking ban at AUB for the total sample and by smoking status. Overall, the largest proportion of students was satisfied to a great or some extent with the ban, considered it justified and viewed it as contributing to a healthy environment. Differences in attitude were mainly between regular smokers and non-smokers. For example, more than $90 \%$ of non-smokers were satisfied to some or a large extent with the policy compared with just $36 \%$ of regular smokers. As expected, the latter majority $(63.8 \%)$ were not at all satisfied with it. Similarly, the majority of non-smokers $(64.5 \%)$ considered the ban to be highly justified, while only $13.8 \%$ of smokers shared the same opinion. Moreover, smokers and non-smokers possessed significantly different views regarding whether the ban helped in creating a healthy environment and whether AUB should become an entirely smoke-free area. While $94 \%$ of non-smokers thought that the ban contributed to some or a large extent in creating a healthy environment, only $67 \%$ of regular smokers believed so. Concerning AUB becoming entirely smoke-free, $45 \%$ of non-smokers supported this prospect as opposed to only $10.2 \%$ of regular smokers.

Regarding the ban's effect on smoking behaviour, the majority $(65 \%)$ of respondents agreed that the ban would help smokers decrease smoking; however, a much lower percentage thought the ban would contribute to smoking cessation. Smokers and non-smokers exhibited significant differences in their viewpoints. Seventy per cent of non-smokers as opposed to $40 \%$ of smokers considered the ban might lead in some or large extent to a decline in smoking. As to its effect on quitting smoking, a large proportion of regular smokers $(84.5 \%)$ and $41.7 \%$ of non-smokers reckoned the ban would have no effect on cessation.

Occasional and ex-smokers were more similar to nonsmokers in their opinion/attitude as depicted in table 3.

\section{Students' attitude towards having a non-smoking policy in public places}

Students' attitude towards enforcing a non-smoking policy in Lebanon varied according to their smoking status whereby regular smokers were more opposed to it. Ex-smokers and occasional smokers were more similar to non-smokers in their attitude as shown in table 4. Overall, a large majority of students supported banning smoking in most public places except outside universities' buildings, night clubs and coffee shops where less

Table 2 Smokers' compliance and behaviour following the ban by gender

\begin{tabular}{|c|c|c|c|c|c|c|}
\hline \multirow[b]{2}{*}{ Variable } & \multicolumn{2}{|l|}{ Total } & \multicolumn{2}{|c|}{ Males } & \multicolumn{2}{|c|}{ Females } \\
\hline & $\mathrm{n}=60$ & Per cent & $\mathrm{n}=39$ & Per cent & $\mathrm{n}=\mathbf{2 1}$ & Per cent \\
\hline \multicolumn{7}{|l|}{ Smoking on campus } \\
\hline Designated areas only & 40 & 72.7 & 27 & 75.0 & 13 & 68.4 \\
\hline Designated and non-designated areas & 15 & 27.3 & 9 & 25.0 & 6 & 31.6 \\
\hline \multicolumn{7}{|c|}{ Received a warning ticket for smoking by an officer on campus } \\
\hline No & 48 & 82.8 & 29 & 78.4 & 19 & 90.5 \\
\hline Yes & 10 & 17.2 & 8 & 21.6 & 2 & 9.5 \\
\hline \multicolumn{7}{|l|}{ Smoking frequency } \\
\hline Increased & 12 & 21.8 & 11 & 31.4 & 1 & 5.0 \\
\hline Decreased & 11 & 20.0 & 7 & 20.0 & 4 & 20.0 \\
\hline Remained the same & 32 & 58.2 & 17 & 48.6 & 15 & 75.0 \\
\hline
\end{tabular}


Table 3 Students' attitude towards AUB's smoking ban by smoking status

\begin{tabular}{|c|c|c|c|c|c|c|c|c|}
\hline \multirow[b]{2}{*}{ Attitude } & \multicolumn{2}{|l|}{ Total } & \multicolumn{2}{|c|}{ Regular smokers } & \multicolumn{2}{|c|}{$\begin{array}{l}\text { Occasional and } \\
\text { ex-smokers }\end{array}$} & \multicolumn{2}{|c|}{ Non-smokers } \\
\hline & $\mathrm{n}=535$ & Per cent & $\mathrm{n}=60$ & Per cent & $\mathrm{n}=59$ & Per cent & $\mathrm{n}=416$ & Per cent \\
\hline \multicolumn{9}{|c|}{ Extent students satisfied with the smoking ban* } \\
\hline Large extent & 311 & 58.6 & 6 & 10.3 & 27 & 45.0 & 278 & 67.5 \\
\hline Some extent & 139 & 26.2 & 15 & 25.9 & 14 & 23.3 & 110 & 26.6 \\
\hline Not at all/not sure & 81 & 15.2 & 37 & 63.8 & 19 & 31.6 & 25 & 6.0 \\
\hline \multicolumn{9}{|c|}{ Extent students consider the ban justified* } \\
\hline Large extent & 302 & 57.2 & 8 & 13.8 & 29 & 49.2 & 265 & 64.5 \\
\hline Some extent & 169 & 32.0 & 26 & 44.8 & 20 & 33.9 & 123 & 29.9 \\
\hline Not at all/not sure & 57 & 10.8 & 24 & 41.4 & 10 & 17.0 & 23 & 5.6 \\
\hline \multicolumn{9}{|c|}{ AUB becoming an entirely smoke-free area* } \\
\hline Agree & 210 & 39.8 & 6 & 10.2 & 19 & 32.8 & 185 & 45.0 \\
\hline Disagree & 230 & 43.6 & 50 & 84.7 & 29 & 50.0 & 151 & 36.7 \\
\hline Undecided & 88 & 16.7 & 3 & 5.1 & 10 & 17.2 & 75 & 18.2 \\
\hline \multicolumn{9}{|c|}{ Extent the ban helped in creating a healthy environment* } \\
\hline Large extent & 313 & 9.2 & 6 & 10.3 & 25 & 42.4 & 282 & 68.4 \\
\hline Some extent & 166 & 31.4 & 33 & 56.9 & 27 & 45.8 & 106 & 25.7 \\
\hline Not at all/not sure & 50 & 9.5 & 19 & 32.8 & 7 & 11.9 & 24 & 5.8 \\
\hline \multicolumn{9}{|c|}{ Extent the ban helps smokers reduce smoking* } \\
\hline Large extent & 88 & 16.7 & 2 & 3.4 & 8 & 13.6 & 78 & 18.9 \\
\hline Some extent & 256 & 48.4 & 21 & 36.2 & 24 & 40.7 & 211 & 51.2 \\
\hline Not at all/not sure & 185 & 35.0 & 35 & 60.3 & 27 & 45.8 & 123 & 29.8 \\
\hline \multicolumn{9}{|c|}{ Extent the ban helps smokers in quitting smoking* } \\
\hline Large extent & 39 & 7.4 & 2 & 3.4 & 5 & 8.8 & 32 & 7.8 \\
\hline Some extent & 149 & 28.3 & 4 & 6.9 & 14 & 24.6 & 131 & 31.8 \\
\hline Not at all/not sure & 339 & 64.3 & 52 & 89.7 & 38 & 66.6 & 249 & 60.4 \\
\hline
\end{tabular}

than half of the sample reported favourable attitudes. Regular smokers and non-smokers exhibited significant differences when it came to banning cigarette smoking in the following places: in ministries, public institutions, schools and university buildings, outside university buildings, as well as in public transportation, workplaces, restaurants, night clubs and coffee shops. For example, while $91.1 \%, 61.1 \%$ and $92.1 \%$ of non-smokers believed that workplaces, nightclubs and public transportation should be smoke-free, respectively, only $55.4 \%, 5.4 \%$ and $78.6 \%$ of regular smokers shared the same opinion. The only two locations that exhibited no significant differences between regular smokers and non-smokers were healthcare facilities and elevators. Here, most students agreed that they should be smoke -free with percentages exceeding $90 \%$.

\section{Barriers to implementation of the smoke-free policy in AUB}

Students were asked what they thought barriers were against the implementation of the non-smoking policy at AUB. The lack of compliance of some students, faculty and staff to the policy was considered a barrier by nearly half the students. Having too few or too crowded smoking areas were viewed as barriers by the majority of regular smokers ( $86 \%$ and $85.7 \%$, respectively); whereas, only $29.9 \%$ and $54.7 \%$ of non-smokers thought the same thing. Furthermore, $35.3 \%$ of non-smokers and $17.9 \%$ of regular smokers considered the lack of strict enforcement of the non-smoking policy as a barrier to tobaccocontrol policies in AUB. Here again, occasional and ex-smokers were more inclined to non-smokers than regular smokers in their opinion/attitude as depicted in table 5 .

\section{DISCUSSION}

The AUB is the first university in Lebanon to institute a non-smoking policy on campus. This provided the opportunity to assess students' compliance with and attitude towards the ban and its impact on their smoking behaviour. These results showed that compliance was high and the smoking ban was effective in curbing some of the students' smoking behaviour. Owing to the crosssectional nature of the study it was not possible to measure whether students reduced their smoking in direct response to the ban. Therefore, we relied on selfreported change in smoking behaviour. Although it was suspected that the ban would positively impact all smokers, unfortunately it did not have this intended effect. Only one in five smokers reported decreased smoking. This could be explained by the fact that although there is a section in the policy on smoking cessation, students are generally unaware of the availability 
Table 4 Students' attitude towards banning cigarette smoking in public places

\begin{tabular}{|c|c|c|c|c|c|c|c|c|}
\hline \multirow[b]{2}{*}{ Attitude } & \multicolumn{2}{|l|}{ Total } & \multicolumn{2}{|c|}{ Regular smokers } & \multicolumn{2}{|c|}{$\begin{array}{l}\text { Occasional and } \\
\text { ex-smokers }\end{array}$} & \multicolumn{2}{|c|}{ Non-smokers } \\
\hline & $\mathrm{n}=535$ & Per cent & $\mathrm{n}=60$ & Per cent & $\mathrm{n}=59$ & Per cent & $\mathrm{n}=416$ & Per cent \\
\hline \multicolumn{9}{|c|}{ Extent students satisfied with the smoking ban* } \\
\hline Large extent & 311 & 58.6 & 6 & 10.3 & 27 & 45.0 & 278 & 67.5 \\
\hline Some extent & 139 & 26.2 & 15 & 25.9 & 14 & 23.3 & 110 & 26.6 \\
\hline Not at all/not sure & 81 & 15.2 & 37 & 63.8 & 19 & 31.6 & 25 & 6.0 \\
\hline \multicolumn{9}{|c|}{ Extent students consider the ban justified ${ }^{*}$} \\
\hline Large extent & 302 & 57.2 & 8 & 13.8 & 29 & 49.2 & 265 & 64.5 \\
\hline Some extent & 169 & 32.0 & 26 & 44.8 & 20 & 33.9 & 123 & 29.9 \\
\hline Not at all/not sure & 57 & 10.8 & 24 & 41.4 & 10 & 17.0 & 23 & 5.6 \\
\hline \multicolumn{9}{|c|}{ AUB becoming an entirely smoke-free area* } \\
\hline Agree & 210 & 39.8 & 6 & 10.2 & 19 & 32.8 & 185 & 45.0 \\
\hline Disagree & 230 & 43.6 & 50 & 84.7 & 29 & 50.0 & 151 & 36.7 \\
\hline Undecided & 88 & 16.7 & 3 & 5.1 & 10 & 17.2 & 75 & 18.2 \\
\hline \multicolumn{9}{|c|}{ Extent the ban helped in creating a healthy environment* } \\
\hline Large extent & 313 & 9.2 & 6 & 10.3 & 25 & 42.4 & 282 & 68.4 \\
\hline Some extent & 166 & 31.4 & 33 & 56.9 & 27 & 45.8 & 106 & 25.7 \\
\hline Not at all/not sure & 50 & 9.5 & 19 & 32.8 & 7 & 11.9 & 24 & 5.8 \\
\hline \multicolumn{9}{|c|}{ Extent the ban helps smokers reduce smoking ${ }^{*}$} \\
\hline Large extent & 88 & 16.7 & 2 & 3.4 & 8 & 13.6 & 78 & 18.9 \\
\hline Some extent & 256 & 48.4 & 21 & 36.2 & 24 & 40.7 & 211 & 51.2 \\
\hline Not at all/not sure & 185 & 35.0 & 35 & 60.3 & 27 & 45.8 & 123 & 29.8 \\
\hline \multicolumn{9}{|c|}{ Extent the ban helps smokers in quitting smoking* } \\
\hline Large extent & 39 & 7.4 & 2 & 3.4 & 5 & 8.8 & 32 & 7.8 \\
\hline Some extent & 149 & 28.3 & 4 & 6.9 & 14 & 24.6 & 131 & 31.8 \\
\hline Not at all/not sure & 339 & 64.3 & 52 & 89.7 & 38 & 66.6 & 249 & 60.4 \\
\hline
\end{tabular}

of a free smoking cessation programme at the university's medical centre for those wanting help. This might explain why the policy did not impact a greater number of students. Consequently, smoking cessation services need to be better advertised so that the students are aware of the help they can get for their tobacco addiction. Another reason why the policy may have not affected smoking behaviour as intended could be that the implementation of AUB's smoking ban was not reinforced by a national smoke-free policy in public places across Lebanon, so as soon as students left the campus, they would go back to their usual habits. Moreover, the policy was not accompanied by an educational campaign to raise awareness regarding the harmful effects of smoking on one's health. A study by Borders et $a l^{14}$ covering undergraduate students at 12 colleges or universities in Texas, showed that compared with different college-level policies and programmes, only the presence of preventive education programmes on campus was associated with lower odds of current cigarette use. ${ }^{14}$ On the other hand, universities which implemented other tobacco-control policies such as smoking cessation programmes and having designated smoking areas were not effective in curbing students' smoking behaviour. For example, the latter two policies/programmes were associated with higher odds of smoking in the study.
Thus, as the authors concluded, implementing strict policies may not be the best way to decrease students' smoking rates, prevention and education programmes might be just as important if not more. While $20 \%$ of regular smokers reported that their smoking decreased, another $21.8 \%$ said that it actually increased following policy enforcement. The increase could be explained by two reasons: First, smokers might have intentionally reported an increase in their smoking frequency to deceive the researchers and to prove the inefficiency of the policy in reducing their smoking behaviour. Second, smoking might have actually increased because since it is viewed as a 'cool' and rebellious behaviour, the more it is prohibited, the cooler the smokers look. ${ }^{15}$

This study has reported also on students' attitude towards the implementation of the non-smoking policy at AUB. Overall students' attitude towards the ban was favourable, but revealed large differences by smoking status. Non-smokers possessed a more favourable attitude towards the smoke-free policy which was evident in their greater satisfaction level, conviction about its need and potential effect in decreasing smoking behaviour. This is to be expected as non-smokers do not want to expose themselves to the adverse health effects of second hand smoke. Other studies in the USA have reached similar findings. A nationally representative study encompassing 
Table 5 Barriers to implementation of the smoke-free policy by smoking status

\begin{tabular}{|c|c|c|c|c|c|c|c|c|}
\hline \multirow[b]{2}{*}{ Attitude } & \multicolumn{2}{|l|}{ Total } & \multicolumn{2}{|c|}{ Regular smokers } & \multicolumn{2}{|c|}{$\begin{array}{l}\text { Occasional and } \\
\text { ex-smokers }\end{array}$} & \multicolumn{2}{|c|}{ Non-smokers } \\
\hline & $\mathrm{n}=535$ & Per cent & $\mathrm{n}=60$ & Per cent & $\mathrm{n}=59$ & Per cent & $\mathrm{n}=416$ & Per cent \\
\hline \multicolumn{9}{|c|}{ Extent students satisfied with the smoking ban* } \\
\hline Large extent & 311 & 58.6 & 6 & 10.3 & 27 & 45.0 & 278 & 67.5 \\
\hline Some extent & 139 & 26.2 & 15 & 25.9 & 14 & 23.3 & 110 & 26.6 \\
\hline Not at all/not sure & 81 & 15.2 & 37 & 63.8 & 19 & 31.6 & 25 & 6.0 \\
\hline \multicolumn{9}{|c|}{ Extent students consider the ban justified* } \\
\hline Large extent & 302 & 57.2 & 8 & 13.8 & 29 & 49.2 & 265 & 64.5 \\
\hline Some extent & 169 & 32.0 & 26 & 44.8 & 20 & 33.9 & 123 & 29.9 \\
\hline Not at all/not sure & 57 & 10.8 & 24 & 41.4 & 10 & 17.0 & 23 & 5.6 \\
\hline \multicolumn{9}{|c|}{ AUB becoming an entirely smoke-free area* } \\
\hline Agree & 210 & 39.8 & 6 & 10.2 & 19 & 32.8 & 185 & 45.0 \\
\hline Disagree & 230 & 43.6 & 50 & 84.7 & 29 & 50.0 & 151 & 36.7 \\
\hline Undecided & 88 & 16.7 & 3 & 5.1 & 10 & 17.2 & 75 & 18.2 \\
\hline \multicolumn{9}{|c|}{ Extent the ban helped in creating a healthy environment* } \\
\hline Large extent & 313 & 9.2 & 6 & 10.3 & 25 & 42.4 & 282 & 68.4 \\
\hline Some extent & 166 & 31.4 & 33 & 56.9 & 27 & 45.8 & 106 & 25.7 \\
\hline Not at all/not sure & 50 & 9.5 & 19 & 32.8 & 7 & 11.9 & 24 & 5.8 \\
\hline \multicolumn{9}{|c|}{ Extent the ban helps smokers reduce smoking* } \\
\hline Large extent & 88 & 16.7 & 2 & 3.4 & 8 & 13.6 & 78 & 18.9 \\
\hline Some extent & 256 & 48.4 & 21 & 36.2 & 24 & 40.7 & 211 & 51.2 \\
\hline Not at all/not sure & 185 & 35.0 & 35 & 60.3 & 27 & 45.8 & 123 & 29.8 \\
\hline \multicolumn{9}{|c|}{ Extent the ban helps smokers in quitting smoking* } \\
\hline Large extent & 39 & 7.4 & 2 & 3.4 & 5 & 8.8 & 32 & 7.8 \\
\hline Some extent & 149 & 28.3 & 4 & 6.9 & 14 & 24.6 & 131 & 31.8 \\
\hline Not at all/not sure & 339 & 64.3 & 52 & 89.7 & 38 & 66.6 & 249 & 60.4 \\
\hline
\end{tabular}

undergraduate students at 119 colleges and universities in the USA revealed that non-smokers were more supportive of different tobacco-control policies such as enforcing smoke-free policies in all campus buildings, student residences, dining areas and campus bars and pubs. ${ }^{16}$ Additionally, non-smokers were more approving of tobacco marketing restrictions (eg, prohibiting tobacco advertising on campus and sponsorship of social events) as well as forbidding tobacco sales on campus. ${ }^{16}$ Similarly, a study by Loukas et $a l^{17}$ with students from five Texas colleges showed that non-smokers and experimental smokers compared with smokers were significantly less opposed to implementing a smoking ban in all buildings and having an entirely smoke-free campus. ${ }^{17}$

Students' attitude towards enforcing a non-smoking policy in public places in Lebanon also differed by smoking status. Regular smokers were more opposing to banning cigarette smoking in ministries, public institutions, workplaces, schools and university buildings etc as aforementioned. The only two locations that smokers and non-smokers agreed on being smoke-free were healthcare facilities and elevators with percentages over $90 \%$. This can be explained by the fact that healthcare facilities provide care for ill patients and smoking would clearly conflict with this purpose. Moreover, given that elevators are confined spaces and have limited air circulation, students most likely agreed that they should be smoke-free so as to respect non-smokers' wishes in breathing in clean air. The results of this study are supported by research conducted in 2004 at AUB and funded by Research for International Tobacco Control (Canada) which showed that in general, there is positive support among young adults including university students for implementing and enforcing tobacco-control policies (unpublished report). The least supported policy, however, was the ban of smoking in restaurants and entertainment places which parallels the research findings.

Barriers to implementation of the smoke-free policy at AUB, as identified by students, were: lack of compliance of some students, Faculty and staff; having too few or too crowded smoking areas; and the lack of strict enforcement of the non-smoking policy. All of the above were considered obstacles with varying agreement between smokers and non-smokers. However, no other published study that looked at barriers to the implementation of a non-smoking policy from a student's perspective was found. Although the lack of compliance was viewed as a barrier, in reality the majority of regular smokers $(73 \%)$ abided by it. This may be because students risked receiving a warning if they were smoking in prohibited areas. In other contexts, compliance has been shown to pose a significant threat to the effective implementation of 
non-smoking policies. Harris et $a l^{18}$ conducted a study to identify efficient strategies that will increase compliance of students to a college campus smoking ban. An intervention consisting of moving smoking receptacles, drawing ground markings and putting more signs regarding the non-smoking policy, as well as distributing reinforcements and reminder cards led to a significant increase in compliance from $33 \%$ to $74 \%$ within the intervention week and remained at $54 \%$ during follow-up. ${ }^{18}$

\section{CONCLUSION}

An education campaign accompanying the policy might be more effective in further reducing current cigarette use; it will also increase smokers' conviction in its necessity. The university should also actively advertise its free smoking cessation services and implement more rigid enforcement measures as this was one of the barriers identified by students. In addition, an awareness based approach is important to illuminate the adverse effects of second hand smoking and to emphasise that nonsmoking policies do not infringe on smokers' rights, rather they aim mostly at protecting non-smokers from breathing in tobacco toxins. Recently Lebanon has passed a law prohibiting smoking in public places. As of 6 March 2012 the Lebanese parliamentary premises were declared a smoke-free zone, with signs prohibiting smoking. This current law was embraced by all public places in Lebanon including schools and universities as of September 2012. ${ }^{19}$ This more universal ban will likely increase the impact of AUB's policy as evidence has indicated that smoking prevalence and incidence is most impacted through implementation of comprehensive national policies.

Acknowledgements The authors would like to thank Ms Zeina Farah and Mr Nabil El Ayoubi for their assistance in data management and analysis. The authors would also like to thank the students who participated in this study and IDRC for their continuous support.

Contributors MC, RN, RAA and JK worked on the conceptualisation of the study. MC and GN were responsible for data collection. MA and GN conducted the analysis of the data. All the authors contributed/gave substantive feedback to the writing of the manuscript. And all authors approved the final manuscript.

Funding This research study was funded through a grant from Research for International Tobacco Control, a secretariat of the International Development Research Center (RITC-IDRC). RITC had no involvement in any stage of the study or its publication.

Competing interests None.
Ethics approval This study has been approved by the Institutional Review Board at AUB and students consented orally to participate in the study.

Provenance and peer review Not commissioned; externally peer reviewed.

Data sharing statement The study"s complete data files and codebook will be added to the Center for Research on Population and Health data archives, and will be made available for students and faculty wishing to make use of the data for their respective courses.

\section{REFERENCES}

1. Steptoe A, Wardle J, Cui W, et al. An international comparison of tobacco smoking, beliefs and risk awareness in university students from 23 countries. Addiction 2002;97:1561-71.

2. American College Health Association. American College Health Association-National College Health Assessment II: Reference Group Executive Summary Spring 2012. Hanover, MD: American College Health Association, 2012.

3. Chaaya M, El Roueiheb Z, Chemaitelly $\mathrm{H}$, et al. Argileh smoking among university students: a new tobacco epidemic. Nicotine Tob Res 2004;6:457-63.

4. Tamim $\mathrm{H}$, Terro $\mathrm{A}$, Kassem $\mathrm{H}$, et al. Tobacco use by university students, Lebanon, 2001. Addiction 2008;98:933-9.

5. Barnoya J, Glantz SA. Cardiovascular effects of secondhand smoke: nearly as large as smoking. Circulation 2005;111:2684-98.

6. Asomaning K, Miller DP, Liu G, et al. Second hand smoke, age of exposure and lung cancer risk. Lung Cancer 2008;61:13-20.

7. Raupach T, Schafer K, Konstantinides S, et al. Secondhand smoke as an acute threat for the cardiovascular system: a change in paradigm. Eur Heart J 2006;27:386-92.

8. Eisner MD, Klein J, Hammond SK, et al. Directly measured second hand smoke exposure and asthma health outcomes. Thorax 2005;60:814-21.

9. Fichtenberg SA, Glantz CM. Effect of smokefree workplaces on smoking behaviour: systematic review. BMJ 2002;325:188.

10. Wechsler H, Lee JE, Rigotti NA. Cigarette use by college students in smoke-free housing. Am J Prev Med 2001;20:202-7.

11. Khuder SA, Milz S, Jordan T, et al. The impact of a smoking ban on hospital admissions for coronary heart disease. Prev Med 2007;45:3-8.

12. Pell JP, Haw S, Cobbe S, et al. Smoke-free legislation and hospitalizations for acute coronary syndrome. N Engl J Med 2008;359:482-91.

13. Nakkash RT, Khalil J, Chaaya M, et al. Building research evidence for policy advocacy: a qualitative evaluation of existing smoke free policies in Lebanon. Asia Pac J Public Health 2010;22(Suppl 3): 168S-74S.

14. Borders TF, Xu KT, Bacchi D, et al. College campus smoking policies and programs and students' smoking behaviours. BMC Public Health 2005:5:74.

15. Lambert TA. The case against smoking bans. Regulation 2006-2007:34-40.

16. Rigotti NA, Regan S, Moran SE, et al. Students' opinion of tobacco control policies recommended for US colleges: a national survey. Tob Control 2003;12:251-6.

17. Loukas A, Garcia MR, Gottlieb NH. Texas College Students' opinions of no-smoking policies, secondhand smoke, and smoking in public places. J Am Coll Health 2006;55:27-32.

18. Harris KJ, Stearns JN, Kovach RG, et al. Enforcing an outdoor smoking ban on a college campus: effects of a multicomponent approach. J Am Coll Health 2009;58:121-6.

19. Ministry of Public Health. The passage of the law: National Tobacco Control Program statement. National Tobacco Control Program. October 2011: 2-6. http://www.tobaccocontrol.gov.lb/Legislation/ Documents/newsletter\%203\%20english.pdf (accessed 12 Mar 2012). 